\title{
The Study of Some Engineering Properties of Teff [Eragrostis teff (ZUCC.) Trotter] Grain Varieties
}

\author{
Gashaw Abebaw Tsegaye ${ }^{1}$, Solomon Abera ${ }^{2}$ \\ ${ }^{1}$ Department of Food Process Engineering, Wolkite University, Wolkite, Ethiopia \\ ${ }^{2}$ Department of Food Technology and Process Engineering, Haramaya University, Dridaw, Ethiopia
}

Email address:

gashaw11abebaw@gmail.com (G. A. Tsegaye)

\section{To cite this article:}

Gashaw Abebaw Tsegaye, Solomon Abera. The Study of Some Engineering Properties of Teff [Eragrostis teff (ZUCC.) Trotter] Grain Varieties. International Journal of Food Engineering and Technology. Vol. 4, No. 1, 2020, pp. 9-12. doi: 10.11648/j.ijfet.20200401.12

Received: January 15, 2020; Accepted: February 25, 2020; Published: March 17, 2020

\begin{abstract}
This study was conducted to generate information on some engineering properties of teff [Eragrostis teff (Zucc.) Trotter] grain varieties. Teff is a unique durable crop grown over a wide range of environmental conditions in Ethiopia and has been utilized as food and supplements for majority of the human diet in Ethiopia Teff is beneficial for those who are lactose intolerant since it is gluten-free. Therefore generation of some information concerning of engineering properties of teff grain and its flour; to investigate and provide concise information and data on selected physical and thermal properties of teff grain and its flour is considered to be important. Six teff varieties namely Quncho (DZ-Cr-387), Felagot (DZ-Cr-442), Tesfa (DZ-Cr457), Kora (DZ-Cr-438), Dukem (DZ-Cr-425) and Dagme (DZ-Cr-43B varieties) were considered and their selection was based on their recent year coverage area and the expected future expansion. Each variety was studied for physical properties. The highest values of the physical properties of the grains which included thousand kernel weights, hectoliter weight, angle of repose, bulk density, moisture content and crude fiber content of grains were $0.29 \mathrm{~g}, 95.67 \mathrm{~kg} / \mathrm{hl}, 23.06^{\circ}, 1.91 \mathrm{~g} / \mathrm{ml}, 10.66 \%$, and $2.92 \%$ for varieties DZ-Cr-457, DZ-Cr-43B, DZ-Cr-438, DZ-Cr-43B, DZ-Cr-438, and DZ-Cr-425, respectively. There were significant $(P<0.05)$ differences among the varieties.
\end{abstract}

Keywords: Teff, Grains, Physical Properties, Angle of Repose

\section{Introduction}

Teff is one of the major and indigenous cereal crops in Ethiopia [1]. Teff is a fine stemmed, tufted annual grass characterized by a large crown, many shoots and a shallow, diverse root system. Teff is a unique durable crop grown over a wide range of environmental conditions in Ethiopia and has been utilized as food and supplements for majority of the human diet in Ethiopia [2]. Teff is an ancient tropical cereal that has its center of origin and diversity in the northern Ethiopian highlands, from where it is believed to have been domesticated. In Ethiopia; it is a major food grain, mainly used to make injera, a traditional fermented Ethiopian pancake. Teff grain size is known to be extremely small with mean length ranging from $0.61-1.17 \mathrm{~mm}$ and mean width ranging from $0.13-0.59 \mathrm{~mm}$ that gives an average thousand kernel weight of 0.264 gram [1]. The teff grain proteins offer an excellent balance among the essential amino acids (Yu et al., 2006). Teff is regarded as a "healthy food", suitable for its employment in novel foods such as baby foods and glutenfree based goods [2]. The attention to teff has been recently increased because of its health benefit.

The knowledge of the engineering properties is useful for both engineers and food scientists and it is also important in data collection in the design of machines, structures, processes and controls; and in determining the efficiency of a machine or an operation.

Currently, consumer's preference towards baked goods with additional (functional and nutritional) value is increasing, forcing food industries to look for more natural nutrient-dense alternatives like grain teff flour for use by the people affected by celiac disease because it is a gluten free cereal grain with high potential. The growing demand for products from teff grain flour due to its nutritional and health benefits is raising the interest of modern food industries and bulk flour milling, flour handling and processing operations of this cereal grain is inevitable. Therefore generation of some information concerning of engineering properties of teff 
grain and its flour; to investigate and provide concise information and data on selected physical, functional, thermal and rheological properties of teff grain and its flour is considered to be important [3].

\section{Literature Review}

\subsection{Teff Production in Ethiopia}

Teff is an important staple cereal in Ethiopia and Eritrea. It is cultivated as a major cereal in Ethiopia and represents 19\% of the total cereal production, with the largest share area (23.42\%, about 2.6 million hectares) under cereal cultivation (Central Statistical Agency, 2010). According to the national estimates of the Central Statistics Authority [4], teff, accounts for about $16 \%$ of the gross grain production of all the cereals cultivated in Ethiopia covering about 2.7 million hectares of land in 2011/12.

\subsection{Health Benefits of Teff}

Although similar to wheat in food value, teff has a higher vitamin and mineral content. When wheat is processed, the germ (the embryo of the berry, which contains a high concentration of vitamins) is removed from the endosperm. The endosperm is then milled into flour. In contrast, teff is almost always produced as whole-grain flour. When it is milled, it is difficult to separate the bran and germ because of the relatively small size of the grain. Because there is a greater portion of germ in milled flour, the nutrient content of teff flour is also higher [5, 6].

\subsection{Chemical Composition of Teff Grain}

Carbohydrates are the major source of energy for human nutrition and play an important role in metabolism and homeostasis. Based on the molecular size and degree of polymerization, carbohydrates can be classified into sugars, oligosaccharides, starch (amylose, amylopectin), and nonstarch polysaccharides. Complex carbohydrates make up 80 percent of the teff grain. It has a starch content of approximately 73 percent, making teff a starchy cereal. The amylose content of 13 teff varieties tested ranged from 20 to 26 percent, comparable to other grains, such as sorghum [1]. Minerals: the difference in mineral content between and within teff varieties is wide ranging. Red teff has a higher iron and calcium content than mixed or white teff [7]. On the other hand, white teff has a higher copper content than red and mixed teff [8].

\section{Material and Methods}

\subsection{Experimental Site}

The experiments were conducted at Hawssa University and Addis Ababa Universities. The experiments like the determination of physical properties of teff grain varieties.

\subsection{Experimental Materials}

The six-teff varieties of Quncho (DZ-Cr-387), Felagot (DZCr-442), Tesfa (DZ-Cr-457), Kora (DZ-Cr-438), Dukem (DZCr-425) and Dagme (DZ-Cr-43B) were obtained from Debre Zeit Agricultural Research Center of the Ethiopian Institute of Agricultural Research (EIAR). These teff varieties were released by the National teff Improvement Program of the Ethiopian Institute of Agricultural Research (EIAR). The six teff varieties were selected based on the color, popularity among the teff grain consumers and the teff grain farming community, high yield, and that some are released recently [9].

\subsection{Statistical Analysis}

All the data we reanalyzed by the two ways of Analysis of Variance (ANOVA) model using the Statistical Analysis software program (SAS), version 9.0 for windows. The results were reported as an average value of triplicate analysis of (mean \pm SD) and were analyzed by Fisher's Least Significance Difference (LSD) method and a statistical significance of $\mathrm{P}<0.05$.

\section{Results and Discussions}

Table 1. Physical Properties of Teff grains Varieties.

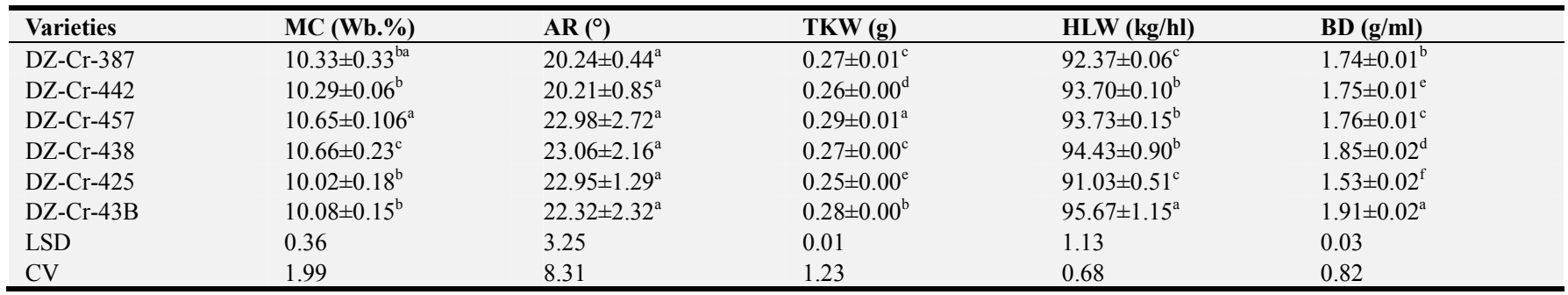

Note $\mathrm{M} . \mathrm{C}=$ Moisture Content, $\mathrm{AR}=$ Angle of Repose, $\mathrm{TKW}=$ Thousand kernel weight, $\mathrm{HLW}=\mathrm{Hectoliter}$ weight, $\mathrm{BD}=\mathrm{Bulk}$ density.

Values within the same column with different superscript letters have significant $(\mathrm{P}<0.05)$ differences.

\subsection{Thousand Kernel Weight}

The measured thousand kernel weight values for each teff grains varieties are shown in Table 1. It is generally expressed in grams per 1000 kernels. There were significant $(\mathrm{P}<0.05)$. Differences among the varieties. The values had ranged from 0.25 to $0.29 \mathrm{~g}$. The highest 
value $0.29 \mathrm{~g}$ was obtained for Tesfa (DZ-Cr-457) while the lowest value $(0.25 \mathrm{~g})$ was for Dukem (DZ-Cr-425). These results were found to be within the ranges between 0.24 and $0.25 \mathrm{~g}$ reported by [1]. Generally speaking, teff grains varieties with a higher thousand kernel weight can be expected to have a greater potential of flour extraction. Thousand kernel weights is the function of grain density and is an important indicator of flour extraction yield [8]. Studies reported that results may vary depending on the types of variety and cultural conditions. The report of [10] indicated that an increase in the grain size leads to increase in thousand kernel weights and grain yield. The differences might also be attributed to the different varieties [11]. Variation in the flour yield may be due to variation in genetic potential, soil type, climatic, maturity of plant, the harvesting time of the seeds and the extraction method used [12].

\subsection{Hectoliter Weight}

The measured hectoliter weight of the teff varieties are presented in Table 1. The values were 92.37, 93.70, 93.73, 94.43, 91.03 and $95.67 \mathrm{~kg} / \mathrm{hl}$ for varieties Quncho (DZ-Cr387), Felagot (DZ-Cr-442), Tesfa (DZ-Cr-457), Kora (DZCr-438), Dukem (DZ-Cr-425) and Dagme (DZ-Cr- 43B), respectively. There were significant $(\mathrm{P}<0.05)$ differences among the varieties. The highest value $(95.67 \mathrm{~kg} / \mathrm{hl})$ was obtained from Dagme (DZ-Cr-43B) and the lowest value $(91.03 \mathrm{~kg} / \mathrm{hl})$ was obtained from Dukem (DZ-Cr-425). These results of the hectoliter weight obtained in this study were found within the ranges between 44.4 and $96.0 \mathrm{Kg} / \mathrm{hl}$ reported by [12]. High hectoliter weight positively correlates with high starches in the kernel [13].

\subsection{Angle of Repose}

Angle of repose is important parameter in the designing of belt conveyors because friction is necessary to hold the grains or flour to the conveying surface without slipping or sliding backward. The frictional properties data are useful in hopper design, since inclination angle of the hopper walls should be greater than the angle of repose to ensure the continuous flow of the grain (gravity flow) (Gossamei, 2015). The angle of repose of the grains of varieties are presented in Table 1. The values were $20.24,20.21,22.98,23.06,22.95$ and $22.32^{\circ}$ for varieties Quncho (DZ-Cr-387), Felagot (DZCr-442), Tesfa (DZ-Cr-457), Kora (DZ-Cr-438), Dukem (DZ-Cr-425) and Dagme (DZ-Cr- 43B), respectively. There were no significant $(\mathrm{P}>0.05)$ differences among the values of the six varieties. The Kora (DZ-Cr-438) had the numerically highest value $23.06^{\circ}$ and Felagot (DZ-Cr-442) the lowest value $20.21^{\circ}$. These results were found to be within the range between 12.40 and $23.75^{\circ}$ reported by [14] who indicated that angle of repose of grain decreased as the size of grain increased especially when the surface of grain becomes more smoothat the storage moisture content [15].

\subsection{Bulk Density}

The bulk density results of the teff grains of different varieties are shown in Table 1 . The values were $1.74,1.75$, $1.76,1.85,1.53$ and $1.91 \mathrm{~g} / \mathrm{ml}$ for varieties Quncho (DZCr-387), Felagot (DZ-Cr-442), Tesfa (DZ-Cr-457), Kora (DZ-Cr-438), Dukem (DZ-Cr-425) and Dagme (DZ-Cr43B), respectively. There were significant $(\mathrm{P}<0.05)$ differences among the varieties. Dagme (DZ-Cr-43B) having the highest value $1.91 \mathrm{~g} / \mathrm{ml}$ whereas Dukem (DZ$\mathrm{Cr}-425)$ the lowest value $1.53 \mathrm{~g} / \mathrm{ml}$. As shown in Table 1 , the bulk density increased also hectoliter weight increase they are direct relationships between bulk density and hectoliter weight of the varieties. The high value of bulk density indicated that more desirable, as the samples would pack better during storage without losing volume, however, the values were comparable among the varieties from each other. These results were found within ranges between 1.53 and $1.91 \mathrm{~g} / \mathrm{ml}$ reported by [16] who indicated that when the bulk density were depending the size of the grain and the particle size of grain generally speak the bulk density can be used to predict packaging requirements.

\subsection{Moisture Content}

The moisture content results of the teff grains varieties are presented in Table 1 . There were significant $(\mathrm{P}<0.05)$ differences among the varieties. The moisture content values were $10.33,10.29,10.65,10.66,10.02$ and $10.08 \%$ for Quncho (DZ-Cr-387), Felagot (DZ-Cr-442), Tesfa (DZ-Cr-457), Kora (DZ-Cr-438), Dukem (DZ-Cr425) and Dagme (DZ-Cr-43B), varieties respectively. These resultswere found to be within the ranges 9.30 and $11.07 \%$ reported for 13 teff varieties by Bultosa, [17]. The low moisture content observed in these studies was a good indicator of their potential to have longer shelf life in storage; it is believed that materials such as flour and starch containing more than $12 \%$ moisture have less storage stability than those with lower moisture content. For this reason, a water content of $10 \%$ is generally specified for flours and other related products. Different food materials have different capacity for absorbing/retaining moisture which may exist as occluded or absorbed water [18].

\section{Conclusions}

The moisture content recorded in the study indicated that the grains are within the recommended safe level for long term storage. The angle of repose values of all the teff varieties at the indicated moisture contents showed that all the grains were in very free flowing category. These facilitate the design of storage and processing facilities of teff grain. The information in regard to thousand kernel weight, bulk density and hectoliter weight relate well and are useful in checking qualities of grains in marketing and flour processing. 


\section{References}

[1] Bultosa, G. 2007. Physico-chemical characteristics of teff grain and flour in 13 teff [Eragrostis teff (Zucc.) Trotter] grain varieties. Applied Sciences Research, 3 (12): 2042-2051.

[2] Dekking, L. S., Y. K. Winkelaar and F. Koning, 2005. The Ethiopian cereal teff in celiac disease. The New Engl. J. Med., 353: $1748-1749$.

[3] Central Statistics Authority (CSA), 2012. Agricultural sample survey 2011/2012 Vol. I. report on area and production for major crops (private peasant holdings, me her season). Statistical Bulletin, May 2012, Addis Ababa, Ethiopia.

[4] Piccinin, D. M., 2002 More about Ethiopian Food: Teff, Department of nutrition and Food Service. From an interview with Tsegazeab Woldetatios, Ph. D., Agriculture Contract Interpreter at Harbor view Medical Center, Christine Wilson editor (4).

[5] Lovis, L. J., 2003 Alternative to Wheat Flour in Baked Goods. J. of Cereal Food World 48. (2): 62-63.

[6] Abebe, W., Collar, C., and Ronda, R., 2015. Impact of variety type and particle size distribution on starch enzymatic hydrolysis and functional properties of teff flours. Carbohydrate Polymers 115, 260-268.

[7] Collar, C., and Angioloni A. (2014b). Pseudo cereals and teff in complex bread making 482 matrices: impact of lipid dynamics on the bread functional and nutritional profiles. 483 Journal of Cereal Science, 59, 145-154.

[8] Zahoor, T., 2003. High molecular weight glutenin subunit composition and multivariate analysis for quality traits of common wheat's grown in Pakistan. PhD. Thesis, Institute of Food Science and Technology. University of Agriculture, Faisalabad, Pakista.

[9] Kanu, P. J. 2011. Biochemical Analysis of Black and White Sesame Seeds from China. American Journal of Biochemistry and Molecular $\quad$ Biology, 1,
http://dx.doi.org/10.3923/ajbmb.2011.145.157.

145-157.

10] Tefera, H and M. Sorrells, 2006. Annual scientific progress report on breeding and genetic basis for teff improvement in Ethiopia. M cK night Foundation's Collaborative Crop Research Program in Teff (MF-CCRP, TefAnnRep_06_1.doc6). Debre Zeit, Ethiopia.

[11] Rahman, M. S., Hossain, M. A., Ahmed, G. M. and Uddin, M. M. 2007. Studies on the Characterization, Lipids and Glyceride Composition of Sesame (Sesamum indicum L.) Seed Oil. Bangladesh Journal of Science and Indian Research, 42, 67-74.

[12] Palmer, J. 2003. How to Brew. Defenestrative Pub Co., New York, 233.

[13] El Fawal, Y., A.; M. A. Tawfik and A. M. El Shal., 2009. Study on physical and engineering properties for grains of some field crop. Misr J. Ag. Eng., 26 (4): 1933- 1951.

[14] Ahmed, I., 2001. Varietal difference in amino acids, composition, milling and baking properties of spring wheat's. Ph. D. Thesis, Department of Food Technology. University of Agriculture, Faisalabad, Pakistan.

[15] Eddy, N. O., Udofia, P. G. and Eyo, D. 2007. Sensory Evaluation of Wheat/Cassava Composite Rock Cake and Effect of Label Information on Acceptance and Preference. African Journal of Biotechnology, 6, 2415-24.

[16] Saturni, L., Ferretti, G., Bacchetti, T., 2010. The gluten-free diet: safety and nutritional quality: review. Nutrients 2, 16-34.

[17] Hasjim, J., Li, E., \& Dhital, S. (2013). Milling of rice grains: The roles of starch 512 structures in the solubility and swelling properties of rice flour. Starch/Stärke, 64, 513 631645 .

[18] Ronda, F., Rivero, P., Caballero, P. A., \& Quilez, J. (2012). High insoluble fibre content 539 increases in vitro starch digestibility in partially baked breads. Journal of Food 540 Science and Nutrition, 63, 971-977. 